Article

\title{
Working from Home After the COVID-19 Pandemic: Do Company Employees Sit More and Move Less?
}

\author{
Mohammad Javad Koohsari ${ }^{1,2,3}$, Tomoki Nakaya ${ }^{4}$, Ai Shibata ${ }^{5}$, Kaori Ishii ${ }^{1}$ (D) and Koichiro Oka ${ }^{1, *(D)}$ \\ 1 Faculty of Sport Sciences, Waseda University, Saitama 359-1192, Japan; \\ javadkoohsari@aoni.waseda.jp (M.J.K.); ishiikaori@waseda.jp (K.I.) \\ 2 Melbourne School of Population and Global Health, The University of Melbourne, Victoria 3010, Australia \\ 3 Behavioural Epidemiology Laboratory, Baker Heart and Diabetes Institute, Victoria 3004, Australia \\ 4 Graduate School of Environmental Studies, Tohoku University, Miyagi 980-8577, Japan; \\ tomoki.nakaya.c8@tohoku.ac.jp \\ 5 Faculty of Health and Sport Sciences, University of Tsukuba, Ibaraki 305-8577, Japan; \\ Shibata.ai.ga@u.tsukuba.ac.jp \\ * Correspondence: koka@waseda.jp
}

check for

updates

Citation: Javad Koohsari, M.; Nakaya, T.; Shibata, A.; Ishii, K.; Oka, K. Working from Home After the COVID-19 Pandemic: Do Company Employees Sit More and Move Less? Sustainability 2021, 13, 939. https://doi.org/10.3390/su13020939

Received: 18 December 2020

Accepted: 15 January 2021

Published: 18 January 2021

Publisher's Note: MDPI stays neutral with regard to jurisdictional claims in published maps and institutional affiliations.

Copyright: (c) 2021 by the authors Licensee MDPI, Basel, Switzerland. This article is an open access article distributed under the terms and conditions of the Creative Commons Attribution (CC BY) license (https:/ / creativecommons.org/licenses/by/ $4.0 /)$.

\begin{abstract}
Background-Several non-pharmaceutical policies, which include stay-at-home orders, mobility restrictions, and quarantine, have been implemented to reduce the spread of novel coronavirus disease 2019 (COVID-19). The present study examines work style changes among company workers after COVID-19 and analyses their effects on workers' domain-specific sedentary and active behaviours. Methods - We analysed data from a nationwide prospective online survey in Japan. The data were obtained in February $2019(n=3200)$ and in July $2020(n=1709)$ from the registered individuals of a Japanese internet research service company. The participants reported work style patterns before and after the outbreak of COVID-19 in the follow-up survey. Domain-specific sedentary behaviours and physical activities were assessed by questionnaires. Paired $t$-tests were used to compare work styles before and after the outbreak of COVID-19. Multivariable linear regression models were used to assess the associations between changes in work style and changes in sedentary behaviours and physical activities. Results. Workers had more working from home days and fewer office-based working days after the outbreak of COVID-19 ( $p<0.001$ and $p<0.001$, respectively). The increase in the number of working from home days per week was significantly associated with increases in work-related sitting time and total sitting time $(b=0.16,95 \%$ CI $0.08,0.24, p<0.001$ and $\mathrm{b}=0.23,95 \%$ CI $0.11,0.36, p<0.001$, respectively). However, it was also associated with a decrease in car sitting time $(\mathrm{b}=-0.04,95 \% \mathrm{CI}-0.06,-0.01, p<0.001)$. In addition, the increase in the number of working from home days was associated with a decrease in work-related moderate physical activity $(\mathrm{b}=-0.06,95 \% \mathrm{CI}-0.10,-0.02, p<0.001)$. Conclusions. Our study provided preliminary evidence of an increase in working from home days in response to COVID-19 in Japan and of how this increase in the number of working from home days has affected workers' sedentary behaviours and physical activities. These findings shed light on the effects of COVID-19 on work styles and workers' sedentary behaviours and physical activity.
\end{abstract}

Keywords: COVID-19; workplaces; sedentary behaviours; physical activity; social distancing; Japan

\section{Introduction}

There is mounting evidence that physical inactivity is associated with a range of chronic diseases, such as type 2 diabetes, cancer, and cardiovascular diseases [1-3]. Sedentary behaviour - too much sitting - has been identified as another emerging health risk factor, which is independent of the level of physical activity [4,5]. Nevertheless, an inactive lifestyle is prevalent around the world [6,7] and causes approximately $9 \%$ of premature deaths globally [8]. Physical inactivity is also an economic burden for health systems [9]: it costs health-care systems at least 53.8 billion international dollars worldwide in 2013 [10]. 
Thus, increasing physical activity and reducing sedentary behaviours are closely linked to several sustainable development goals (SDGs) [11,12].

Over the last decade, technological advancement and opportunities for automation have caused many jobs to become more sedentary. Working adults can accumulate a high portion of sedentary behaviours and become an at-risk population for having a sedentary lifestyle [13-16]. For example, a study that was conducted in Singapore found that working adults spent between $69-76 \%$ of their daily waking time engaging in sedentary behaviours [14]. Another study, which was conducted in Australia, found that employees spent most of their working hours in a sedentary behaviour with prolonged bouts of sitting time [13]. Following the socio-ecological framework [17], multiple individual, interpersonal, and urban design factors must be considered in promoting physical activity and reducing sedentary behaviours among workers. Additional evidence-based information on the socio-ecological factors that influence workers' active and sedentary behaviours is needed to support the development of effective interventions.

The novel coronavirus disease 2019 (COVID-19) was first reported in late 2019 in Wuhan, Hubei Province, China, and has spread globally. On 11 March 2020, COVID-19 was announced as a pandemic by the World Health Organization (WHO) [18]. In Japan, a state of emergency was declared by the government on 7 April 2020 in order to limit the spread of COVID-19 [19]. This state of emergency allowed prefectural governors to ask residents to limit their non-essential trips, stay at home as much as possible, and ask places such as cinemas and museums to restrict their operation. Unlike with 'lockdowns' in several other countries, there was no penalty or legal force under Japanese law for people or companies who disobeyed the request. In the present pandemic of COVID-19, several non-pharmaceutical policies, such as stay-at-home orders, school closures, gathering bans, mobility restrictions, and quarantine, have been implemented to reduce the spread of COVID-19 [20-22]. Several studies have provided preliminary evidence on how these policies may influence people's mobility behaviours [23-25]. Work style has likely also been affected by these policies. For instance, 'working from home' policies have been introduced by many companies in response to COVID-19. A Japanese government survey showed that approximately $35 \%$ of respondents worked remotely after the COVID-19 epidemic [26]. It is of interest to examine whether such a work style change affects workers' sedentary behaviours and physical activities. However, no study, to the best of our knowledge, has yet explored the association between changes in work style after COVID-19 and longitudinal changes in workers' sedentary behaviours and physical activities.

Therefore, the current study examines the work style changes among company workers after COVID-19 and analyses their effects on workers' domain-specific sedentary and active behaviours.

\section{Materials and Methods}

\subsection{Study Design and Sample}

We analysed data from a nationwide prospective online survey in Japan. The data were obtained in 2019 and 2020 from the registered individuals of a Japanese internet research service company (MyVoice Communication, Inc. Tokyo, Japan). This company's database contains sociodemographic information on one million individuals across Japan who voluntarily participated in this database. On 22 February 2019, an invitation e-mail with a link to participate in the survey was sent to 45,659 workers (aged 20 to 59 years) who were randomly selected from the database. To minimize possible selection bias, the potential participants were stratified by sex and age group (20s, 30s, 40s, and 50s). A total of 3200 workers responded to the survey (a response rate of $7.00 \%$ ): 1600 participants of each sex and 800 participants of each age group. Of these respondents, 2921 individuals were eligible to take part in a follow-up survey on 8 July 2020. A total of 1709 individuals completed the follow-up survey (53.4\% of the baseline participants) because 279 individuals had resigned from the company's database. Cash rewards that were valued at 140 and 120 yen were provided as incentives to participate in the baseline and follow-up surveys, respectively. Totals of 2466 
and 1318 participants at baseline and follow-up, respectively, who reported their occupation as company employees were included in this study (Figure 1). All participants signed an online informed consent form. This study received prior approval from the Institutional Ethics Committee of Waseda University (2020-135).

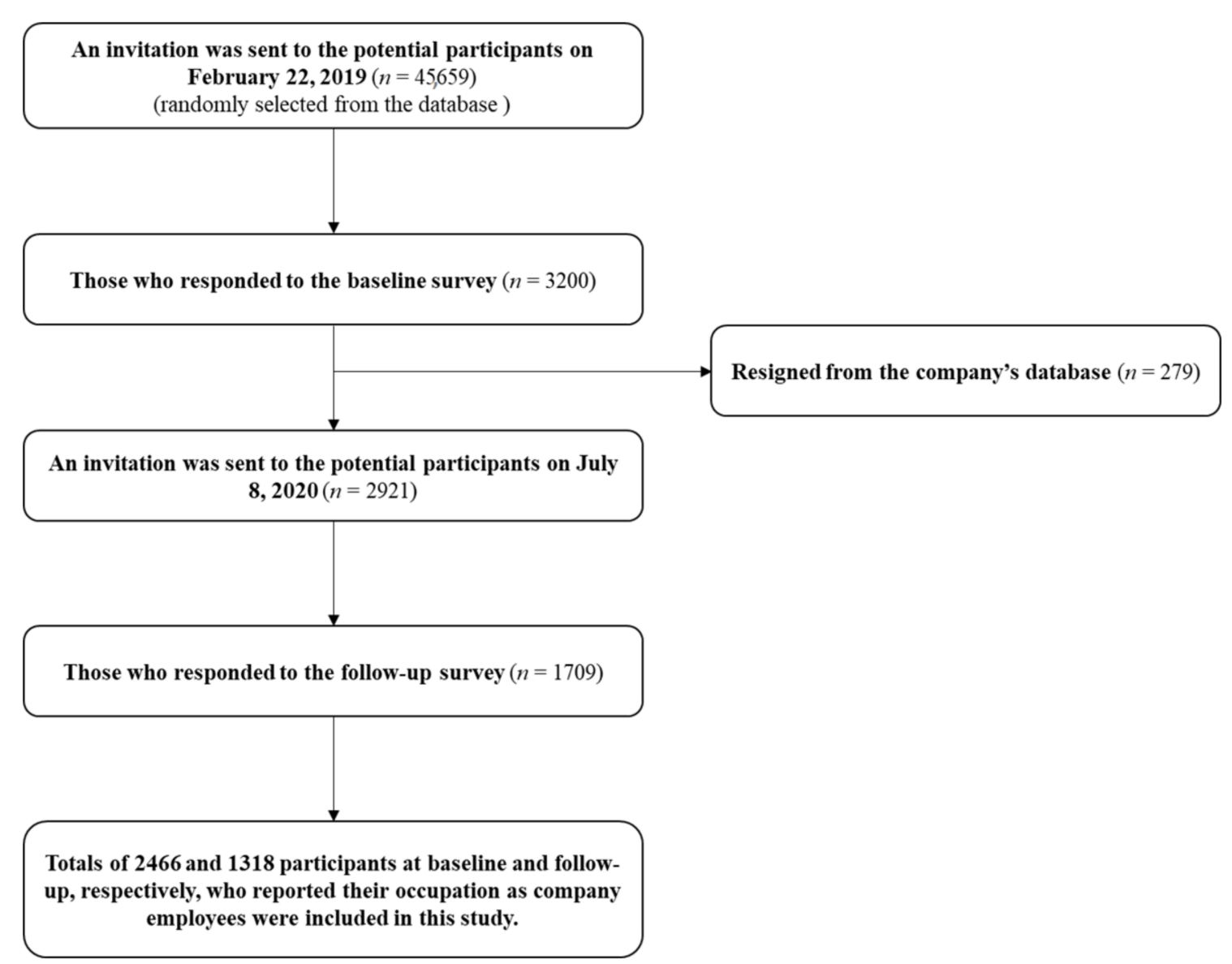

Figure 1. Flow diagram of participants in the study.

\subsection{Measures}

\subsubsection{Work Style Patterns}

Work style patterns before and after the outbreak of COVID-19 were reported by participants in the follow-up survey. The participants were asked to state their total numbers of working and non-working days in a typical week before and after the first large outbreak of COVID-19 in early April 2020. For working days, participants also reported the total number of days they worked at their place of employment or worked from home.

\subsubsection{Sedentary Behaviours}

A Japanese 6-item questionnaire with a 1-week recall period was used to evaluate domain-specific sedentary behaviours [27]. Participants reported their daily average sedentary behaviours over the past seven days in six domains: driving or riding by car; using public transport; at work; watching television, videos, or DVDs; using a computer, cell phone, or tablet PC outside of working hours; and leisure (excluding watching television, videos, and DVDs). This questionnaire has high reliability and validity [27]. Average workday and non-workday values of the total sedentary time were calculated by summing all six domains separately for workdays and non-workdays. Average daily values of total sedentary time and each domain's sedentary time were also assessed by weighting according to the numbers of workdays and non-workdays. 


\subsubsection{Physical Activities}

The Global Physical Activity Questionnaire (GPAQ) was used to measure domainspecific physical activities [28]. The method of cleaning and scoring the GPAQ data has been described in detail elsewhere [29]. In brief, this self-reported questionnaire consists of 16 questions that assess physical activities in three domains, namely, work, transport, and leisure. The GPAQ has acceptable validity and reliability in the Japanese adult population [30]. We calculated the average daily hours of work-related vigorous physical activity, work-related moderate physical activity, transport-related physical activity, leisure vigorous physical activity, leisure moderate physical activity, and total physical activity. The absolute changes in sedentary behaviours and physical activity before and after the outbreak of COVID-19 were estimated by subtracting baseline values from follow-up values.

\subsubsection{Sociodemographics}

The following sociodemographic characteristics were self-reported by the participants at baseline: age, sex (female or male), marital status (single or couple), highest education (tertiary, below tertiary, or other), and gross annual individual income $(<¥ 4,000,000$ or $\geq ¥ 4,000,000)$.

\subsection{Statistical Analysis}

Descriptive statistics, which included means, standard deviations, and frequencies, were calculated for the baseline sociodemographic variables. Paired $t$-tests were used to compare the work styles before and after the outbreak of COVID-19. Multivariable linear regression models were used to estimate the associations between changes in work style and changes in sedentary behaviours and physical activities. The regression models were adjusted according to the sociodemographic variables (age, sex, marital status, highest education, and gross annual household income) and the changes in working days before and after the outbreak of COVID-19. The regression models were also adjusted according to the baseline sedentary behaviours and physical activities to account for the potential effects of the baseline values on the scores. Normality assumptions were checked by the $Q Q$ plots of the residuals. For all point estimates of unstandardized regression coefficients (b), $95 \%$ confidence intervals (CIs) were estimated. A complete-case analysis was conducted because the proportion of missing data for our variables of interest was low (5\%) [31]. Analyses were conducted using Stata 15.0 (Stata Corp, College Station, TX, USA), and the level of significance was set at $p<0.05$.

\section{Results}

Table 1 shows baseline and follow-up characteristics of study participants. At baseline, the participants had an average age of 39.6 years $(S D=10.7)$, and $50.9 \%$ were male $(n=1254)$. Most participants were single $(n=1392,56.4 \%)$, had tertiary education $(n=1989,80.7 \%)$, and had an annual gross individual income lower than $¥ 4,000,000(n=1381,56.0 \%)$.

Table 2 presents the changes in work style before and after the outbreak of COVID19. There were significant differences in work style between the two periods: workers had more working from home days and fewer office-based working days after the first COVID-19 major outbreak in Japan in April 2020 ( $p<0.001$ and $p<0.001$, respectively). The mean number of working days per week was significantly lower after the outbreak of COVID-19 $(p<0.001)$.

Table 3 presents the associations of the absolute changes in working from home days with those in workers' domain-specific sedentary behaviours. An increase in working from home days was significantly associated with increases in work-related sitting time and total sitting time $(b=0.16,95 \%$ CI $0.08,0.24, p<0.001$ and $b=0.23,95 \%$ CI 0.11 , $0.36, p<0.001$, respectively). However, an increase in working from home days was also associated with a decrease in car sitting time $(b=-0.04,95 \% \mathrm{CI}-0.06,-0.01, p<0.001)$. 
No significant associations were identified between changes in work style and changes in public transportation sitting, TV viewing time, PC use sitting, or other leisure sitting time.

Table 1. Characteristics of study participants.

\begin{tabular}{lcc}
\hline \multirow{2}{*}{ Variable } & \multicolumn{2}{c}{ Mean $(S D)$ or $N$ (\%) } \\
\cline { 2 - 3 } & Baseline $(\boldsymbol{N}=\mathbf{2 4 6 6 )}$ & Follow-up $(\mathbf{N}=\mathbf{1 3 1 8})$ \\
\hline Age (years) & $39.6(10.7)$ & $42.5(10.4)$ \\
Sex & $1212(49.1)$ & $657(49.8)$ \\
Male & $1254(50.9)$ & $661(50.2)$ \\
Marital status & & \\
Single & $1392(56.4)$ & $696(52.8)$ \\
Couple & $1074(43.6)$ & $622(47.2)$ \\
Highest education & & $1078(81.8)$ \\
Tertiary & $1989(80.7)$ & $240(18.2)$ \\
Below tertiary & $477(19.3)$ & $691(52.4)$ \\
Gross annual individual income & & $627(47.6)$ \\
$<¥ 4,000,000$ & $1381(56.0)$ & \\
$\geq ¥ 4,000,000$ & $1085(44.0)$ &
\end{tabular}

Table 2. Changes in work style before and after the outbreak of COVID-19 ( $n=1318)$.

\begin{tabular}{lccc}
\hline & \multicolumn{2}{c}{ Mean (S.D.) } & \multirow{2}{*}{$p$-Value } \\
\cline { 2 - 3 } & Before (February 2019) & After (July 2020) \\
\hline Office-based working (days/week) & $4.91(0.84)$ & $4.05(1.71)$ & $0.000 *$ \\
Working from home (days/week) & $0.16(0.79)$ & $0.96(1.65)$ & $0.000 *$ \\
Working days (days/week) & $5.07(0.47)$ & $5.01(0.60)$ & $0.000 *$ \\
\hline *Statistically significant based on paired-sample $t$-tests. &
\end{tabular}

Table 3. Associations between absolute changes in working from home days and changes in workers' domain-specific sedentary behaviours (complete data of 1086 individuals).

\begin{tabular}{|c|c|c|c|c|c|c|c|}
\hline & $\begin{array}{l}\text { Car Sitting Time } \\
\text { (Hour/Day) }\end{array}$ & $\begin{array}{c}\text { Public } \\
\text { Transportation } \\
\text { Sitting } \\
\text { (Hour/Day) }\end{array}$ & $\begin{array}{l}\text { Work-Related } \\
\text { Sitting Time } \\
\text { (Hour/Day) }\end{array}$ & $\begin{array}{l}\text { TV Viewing } \\
\text { Time } \\
\text { (Hour/Day) }\end{array}$ & $\begin{array}{c}\text { PC Use Sitting } \\
\text { Time } \\
\text { (Hour/Day) }\end{array}$ & $\begin{array}{l}\text { Other Leisure } \\
\text { Sitting Time } \\
\text { (Hour/Day) }\end{array}$ & $\begin{array}{c}\text { Total Sitting } \\
\text { Time } \\
\text { (Hour/Day) }\end{array}$ \\
\hline & $\begin{array}{c}\text { b (95\% CI) } \\
p \text {-Value }\end{array}$ & $\begin{array}{c}\text { b (95\% CI) } \\
p \text {-Value }\end{array}$ & $\begin{array}{c}\text { b (95\% CI) } \\
p \text {-Value }\end{array}$ & $\begin{array}{c}\text { b (95\% CI) } \\
p \text {-Value }\end{array}$ & $\begin{array}{c}\text { b (95\% CI) } \\
p \text {-Value }\end{array}$ & $\begin{array}{c}\text { b (95\% CI) } \\
p \text {-Value }\end{array}$ & $\begin{array}{c}\text { b (95\% CI) } \\
p \text {-Value }\end{array}$ \\
\hline $\begin{array}{c}\text { Working from } \\
\text { home } \\
\text { (days/week) }\end{array}$ & $\begin{array}{l}-0.04(-0.06 \\
-0.01) 0.003 *\end{array}$ & $\begin{array}{c}-0.00(-0.02 \\
0.02) 0.862\end{array}$ & $\begin{array}{c}0.16(0.08,0.24) \\
0.000^{*}\end{array}$ & $\begin{array}{c}0.05(-0.00,0.10) \\
0.059\end{array}$ & $\begin{array}{c}0.04(-0.01,0.09) \\
0.115\end{array}$ & $\begin{array}{c}0.00(-0.03,0.04) \\
0.889\end{array}$ & $\begin{array}{c}0.23(0.11,0.36) \\
0.000^{*}\end{array}$ \\
\hline
\end{tabular}

b: unstandardized regression coefficients; CI: confidence interval. All models were adjusted for age, sex, marital status, highest education, gross annual household income, changes in working days, and baseline sedentary behaviours. ${ }^{*} p<0.05$.

Table 4 presents the associations of the absolute changes in working from home days with those in workers' domain-specific physical activities. An increase in working from home days was associated with a decrease in work-related moderate physical activity $(b=-0.06,95 \% \mathrm{CI}-0.10,-0.02, p<0.001)$. There were no significant associations between the change in working from home days and changes in work-related vigorous physical activity, transport-related physical activity, leisure vigorous physical activity, leisure moderate physical activity, or total physical activity. 
Table 4. Associations between absolute changes in working from home days and changes in workers' domain-specific physical activities (complete data of 1315 individuals).

\begin{tabular}{|c|c|c|c|c|c|c|}
\hline & $\begin{array}{l}\text { Work-Related Vigorous } \\
\text { Physical Activity } \\
\text { (Hour/Day) }\end{array}$ & $\begin{array}{l}\text { Work-Related Moderate } \\
\text { Physical Activity } \\
\text { (Hour/Day) }\end{array}$ & $\begin{array}{l}\text { Transport-Related Physical } \\
\text { Activity (Hour/Day) }\end{array}$ & $\begin{array}{l}\text { Leisure Vigorous Physical } \\
\text { Activity (Hour/Day) }\end{array}$ & $\begin{array}{l}\text { Leisure Moderate Physical } \\
\text { Activity (Hour/Day) }\end{array}$ & $\begin{array}{l}\text { Total Physical Activity } \\
\text { (Hour/Day) }\end{array}$ \\
\hline & b (95\% CI)p-value & b $(95 \%$ CI) $p$-Value & b $(95 \%$ CI) $p$-Value & b $(95 \%$ CI) $p$-Value & b $(95 \%$ CI) $p$-Value & b $(95 \%$ CI) $p$-Value \\
\hline $\begin{array}{l}\text { Working from home } \\
\text { (days/week) }\end{array}$ & $0.02(-0.01,0.05) 0.147$ & $-0.06(-0.10,-0.02) 0.004$ * & $0.02(-0.01,0.04) 0.124$ & $0.01(-0.01,0.02) 0.440$ & $-0.00(-0.02,0.02) 0.897$ & $-0.04(-0.11,0.03) 0.256$ \\
\hline
\end{tabular}

b: unstandardized regression coefficients; CI: confidence interval. All models were adjusted for age, sex, marital status, highest education, gross annual household income, changes in working days, and baseline physical activities. ${ }^{*} p<0.05$.

\section{Discussion}

This study explored the changes in workers' work styles that occurred after the outbreak of COVID-19. It also examined the associations of the changes in workers' work styles with the longitudinal changes in their sedentary behaviours and physical activities after the COVID-19 outbreak. We found that workers in Japan reported more working from home days after the outbreak of COVID-19 compared with before it. These findings are consistent with the results of several studies that were conducted in other countries and showed an increase in working from home after the start of the COVID-19 epidemic [32-35]. A study that was conducted in the US using a nationally representative sample found that approximately one-third of workers changed to remote working between February and May 2020 [32]. Another study, which was conducted in the Netherlands, found that the percentage of workers who were working from home increased from $6 \%$ to $39 \%$ since the COVID-19 epidemic began [34]. In Canada, approximately 39\% of workers were teleworking during March 2020, compared with approximately 13\% in 2018 [35]. Our study extends these findings into Japan, where workers have among the most extended working hours in the world [36]. There have been speculations that working from home may become a new norm even after this pandemic [37-39]. Having homes as workplaces will introduce several new opportunities and challenges from various social, economic, urban design, and health perspectives $[40,41]$. It is necessary to investigate how working from home may affect workers' health behaviours and outcomes. Future longitudinal studies are needed to explore whether these increases in working from home that were triggered by the COVID-19 epidemic will be permanent.

Our results demonstrate that an increase in working from home days was associated with increases in work-related and total sitting times. An increase in working days was also unfavourably associated with moderate physical activity at work. To the best of our knowledge, no previous studies have assessed whether changes in work style were associated with longitudinal changes in workers' sedentary behaviours and physical activities after the COVID-19 epidemic. Therefore, it was not possible to compare these findings with those of any previous studies. These findings are in line with those of a previous cross-sectional study that examined associations between working from home and sedentary behaviour [42]. McDowell et al. [42] found that workers who are working from home or lost their job spent more time engaged in sedentary behaviours than those whose job remained unchanged after the outbreak of COVID-19. However, we found that working from home was associated with a shorter sitting time in cars, since working from home did not require commuting to work. These results highlight that working from home may have distinctive effects on each sedentary behaviour and physical activity in each domain. Socioecological models suggest that multiple factors need to be taken into account in promoting health behaviours. Changes in work style may also affect workers' sedentary and active behaviours. Additional evidence on the effects of COVID-19 social distancing policies on domain-specific sedentary behaviours and physical activities is needed to inform the development of efficient public health interventions within the socio-ecological framework.

The main limitation of our study is that the self-reported measures of sedentary behaviours and physical activities and the work style measures at baseline are subject to recall bias. The assessment of longitudinal domain-specific sedentary behaviours and physical activities and the use of national data are advantages of this study. While this is a 
national study of participants, we cannot generalise the findings to all company workers or other professions.

\section{Conclusions}

The COVID-19 epidemic has caused significant changes in workers' work styles worldwide. Our study provided preliminary evidence of an increase in working from home in response to COVID-19 in Japan and explored how this increase in working from home has affected workers' sedentary behaviours and physical activities. Further evidence is needed to explore whether the effects of the outbreak of COVID-19 on work style are permanent and how changes in work style may affect workers' health behaviours and outcomes. This information is necessary to develop efficient programs and interventions to promote an active lifestyle among workers with the socio-ecological framework.

Author Contributions: M.J.K. and K.O. conceived the idea, analysed the data, and drafted the paper. T.N. assisted with the statistical analysis. T.N., A.S. and K.I. contributed to the writing and assisted with the interpretation. All authors have read and agreed to the published version of the manuscript.

Funding: T.N. was supported by the JSPS KAKENHI (\#20H00040). K.O. is supported by a Grant-inAid for Scientific Research (No. 20H04113) from the Japan Society for the Promotion of Science.

Institutional Review Board Statement: This study received prior approval from the Institutional Ethics Committee of Waseda University (2020-135).

Informed Consent Statement: Informed consent was obtained from all subjects involved in the study.

Data Availability Statement: The datasets generated during and/or analysed during the current study are not publicly available due to ethical considerations but may be available from the corresponding author on reasonable request.

Conflicts of Interest: The authors declare no conflict of interest.

\section{References}

1. Durstine, J.L.; Gordon, B.; Wang, Z.; Luo, X. Chronic disease and the link to physical activity. J. Sport Heal. Sci. 2013, 2, 3-11. [CrossRef]

2. Thornton, J.S.; Frémont, P.; Khan, K.; Poirier, P.; Fowles, J.; Wells, G.D.; Frankovich, R.J. Physical activity prescription: A critical opportunity to address a modifiable risk factor for the prevention and management of chronic disease: A position statement by the Canadian Academy of Sport and Exercise Medicine: Table 1. Br. J. Sports Med. 2016, 50, 1109-1114. [CrossRef]

3. Dietz, W.H.; Douglas, C.E.; Brownson, R.C. Chronic Disease Prevention: Tobacco Avoidance, Physical Activity, and Nutrition for a Healthy Start. JAMA 2016, 316, 1645-1646.

4. Owen, N.; Sparling, P.B.; Healy, G.N.; Dunstan, D.W.; Matthews, C.E. Sedentary Behavior: Emerging Evidence for a New Health Risk; Elsevier: Amsterdam, The Netherlands, 2010; Volume 85, pp. 1138-1141.

5. Young, D.R.; Hivert, M.-F.; Alhassan, S.; Camhi, S.M.; Ferguson, J.F.; Katzmarzyk, P.T.; Lewis, C.E.; Owen, N.; Perry, C.K.; Siddique, J.; et al. Sedentary Behavior and Cardiovascular Morbidity and Mortality: A Science Advisory from the American Heart Association. Circulation 2016, 134, 0440. [CrossRef]

6. Guthold, R.; A Stevens, G.; Riley, L.M.; Bull, F.C. Worldwide trends in insufficient physical activity from 2001 to 2016 : A pooled analysis of 358 population-based surveys with 1.9 million participants. Lancet Glob. Heal. 2018, 6, 3577. [CrossRef]

7. Kohl, H.W., 3rd; Craig, C.L.; Lambert, E.V.; Inoue, S.; Alkandari, J.R.; Leetongin, G.; Kahlmeier, S. Group LPASW: The pandemic of physical inactivity: Global action for public health. Lancet 2012, 380, 294-305.

8. Lee, I.-M.; Shiroma, E.J.; Lobelo, F.; Puska, P.; Blair, S.N.; Katzmarzyk, P.T. Effect of physical inactivity on major non-communicable diseases worldwide: An analysis of burden of disease and life expectancy. Lancet 2012, 380, 219-229. [CrossRef]

9. Pratt, M.; Norris, J.; Lobelo, F.; Roux, L.; Wang, G. The cost of physical inactivity: Moving into the 21st century: Table 1. Br. J. Sports Med. 2014, 48, 171-173. [CrossRef]

10. Ding, D.; Lawson, K.D.; Kolbe-Alexander, T.; Finkelstein, E.A.; Katzmarzyk, P.T.; Van Mechelen, W.; Pratt, M. The economic burden of physical inactivity: A global analysis of major non-communicable diseases. Lancet 2016, 388, 1311-1324. [CrossRef]

11. Department of Economic and Social Affairs. United Nations: Transforming Our World: The 2030 Agenda for Sustainable Development; Department of Economic and Social Affairs: New York, NY, USA, 2015.

12. World Health Organization. Guidelines for Physical Activity and Sedentary Behaviour; World Health Organization: Geneva, Switzerland, 2020. 
13. Thorp, A.A.; Healy, G.N.; Winkler, E.; Clark, B.K.; Gardiner, P.A.; Owen, N.; Dunstan, D.W. Prolonged sedentary time and physical activity in workplace and non-work contexts: A cross-sectional study of office, customer service and call centre employees. Int. J. Behav. Nutr. Phys. Act. 2012, 9, 128. [CrossRef]

14. Müller-Riemenschneider, F.; Ng, S.H.X.; Koh, D.; Chu, A.H.Y. Objectively Measured Patterns of Activities of Different Intensity Categories and Steps Taken Among Working Adults in a Multi-ethnic Asian Population. J. Occup. Environ. Med. 2016, $58,0745$. [CrossRef]

15. Hadgraft, N.T.; Healy, G.N.; Owen, N.; Winkler, E.A.H.; Lynch, B.M.; Sethi, P.; Eakin, E.G.; Moodie, M.; Lamontagne, A.D.; Wiesner, G.; et al. Office workers' objectively assessed total and prolonged sitting time: Individual-level correlates and worksite variations. Prev. Med. Rep. 2016, 4, 184-191. [CrossRef]

16. Sugiyama, T.; Hadgraft, N.; Clark, B.K.; Dunstan, D.W.; Owen, N. Sitting at work \& waist circumference-A cross-sectional study of Australian workers. Prev. Med. 2020, 141, 106243. [CrossRef]

17. Sallis, J.F.; Owen, N. Fisher E: Ecological models of health behavior. Health Behav. Theory Res. Practice 2015, 5, $43-64$.

18. World Health Organization. WHO Director-General's Opening Remarks at the Media Briefing on COVID-19; WHO: Geneva, Switzerland, 2020.

19. The Prime Minister of Japan and His Cabinet: Declaration of a State of Emergency in Response to the Novel Coronavirus Disease. 2020. Available online: https://japan.kantei.go.jp/ongoingtopics/_00020.html (accessed on 17 January 2021).

20. Sen-Crowe, B.; McKenney, M.; Elkbuli, A. Social distancing during the COVID-19 pandemic: Staying home save lives. Am. J. Emerg. Med. 2020, 38, 1519-1520. [CrossRef]

21. Masters, N.B.; Shih, S.-F.; Bukoff, A.; Akel, K.B.; Kobayashi, L.C.; Miller, A.L.; Harapan, H.; Lu, Y.; Wagner, A.L. Social distancing in response to the novel coronavirus (COVID-19) in the United States. PLoS ONE 2020, 15, e0239025. [CrossRef]

22. Mahase, E. Covid-19: UK starts social distancing after new model points to 260000 potential deaths. BMJ 2020, 368, m1089. [CrossRef]

23. Huang, X.; Li, Z.; Jiang, Y.; Li, X.; Porter, D. Twitter reveals human mobility dynamics during the COVID-19 pandemic. PLoS ONE 2020, 15, e0241957. [CrossRef]

24. Tison, G.H.; Avram, R.; Kuhar, P.; Abreau, S.; Marcus, G.M.; Pletcher, M.J.; Olgin, J. Worldwide Effect of COVID-19 on Physical Activity: A Descriptive Study. Ann. Intern. Med. 2020, 173, 767-770. [CrossRef]

25. Hadjidemetriou, G.M.; Sasidharan, M.; Kouyialis, G.; Parlikad, A.K. The impact of government measures and human mobility trend on COVID-19 related deaths in the UK. Transp. Res. Interdiscip. Perspect. 2020, 6, 100167. [CrossRef]

26. Japan Cabinet Office. Survey on Changes in Lifestyle and Behavior under the Influence of the New Coronavirus Infection; Cabinet Office: Tokyo, Japan, 2020.

27. Ishii, K.; Shibata, A.; Kurita, S.; Yano, S.; Inoue, S.; Sugiyama, T.; Owen, N.; Oka, K. Validity and Reliability of Japanese-Language Self-reported Measures for Assessing Adults Domain-Specific Sedentary Time. J. Epidemiol. 2017, 28, 149-155. [CrossRef]

28. Armstrong, T.; Bull, F. Development of the World Health Organization Global Physical Activity Questionnaire (GPAQ). J. Public Health 2006, 14, 66-70. [CrossRef]

29. World Health Organization. Global Physical Activity Questionnaire (GPAQ) Analysis Guide; World Health Organization: Geneva, Switzerland, 2012.

30. Bull, F.C.; Maslin, T.S.; Armstrong, T. Global Physical Activity Questionnaire (GPAQ): Nine Country Reliability and Validity Study. J. Phys. Act. Health 2009, 6, 790-804. [CrossRef]

31. Jakobsen, J.C.; Gluud, C.; Wetterslev, J.; Winkel, P. When and how should multiple imputation be used for handling missing data in randomised clinical trials-A practical guide with flowcharts. BMC Med. Res. Methodol. 2017, 17, 162.

32. Brynjolfsson, E.; Horton, J.; Ozimek, A.; Rock, D.; Sharma, G.; TuYe, H.-Y. COVID-19 and Remote Work: An Early Look at US Data. NBER 2020. [CrossRef]

33. Bick, A.; Blandin, A.; Mertens, K. Work from Home after the COVID-19 Outbreak. Available online: https://www.dallasfed.org/ -/media/documents/research/papers/2020/wp2017r1.pdf (accessed on 17 January 2021).

34. De Haas, M.; Faber, R.; Hamersma, M. How COVID-19 and the Dutch 'intelligent lockdown'change activities, work and travel behaviour: Evidence from longitudinal data in the Netherlands. Transp. Res. Interdiscip. Perspect. 2020, 6, 100150.

35. Deng, Z.; Morissette, R.; Messacar, D. Running the Economy Remotely: Potential for Working From Home during and after COVID-19. Statistics Canada Catalogue. Available online: https://www150.statcan.gc.ca/n1/pub/45-28-0001/2020001/article/ 00026-eng.htm (accessed on 17 January 2021).

36. Ono, H. Why do the japanese work long hours. Soc. Perspect. Long Work. Hours Jpn. Jpn. Labor Issues 2018, 2, 35-49.

37. Sander, L. Coronavirus Could Spark A Revolution in Working from Home. Are We Ready? Available online: https://theconversation. com/coronavirus-could-spark-a-revolution-in-working-from-home-are-we-ready-133070 (accessed on 17 January 2021).

38. Ozimek, A. The Future of Remote Work. SSRN Electron. J. 2020. [CrossRef]

39. Hite, L.M.; McDonald, K.S. Careers after COVID-19: Challenges and changes. Hum. Resour. Dev. Int. 2020, 23, 427-437. [CrossRef]

40. Doling, J.; Arundel, R. The Home as Workplace: A Challenge for Housing Research. Hous. Theory Soc. 2020, 2020, 1-20. [CrossRef]

41. Kaushik, M.; Guleria, N. The Impact of Pandemic COVID -19 in Workplace. Eur. J. Bus. Manag. 2020, 12, 9-18. [CrossRef]

42. McDowell, C.P.; Herring, M.P.; Lansing, J.; Brower, C.; Meyer, J. Working from Home and Job Loss Due to the COVID-19 Pandemic Are Associated With Greater Time in Sedentary Behaviors. Front. Public Health 2020, 8, 597619. [CrossRef] 